\title{
CUSTEIO THROUGHPUT COMO PRÁTICA DE CUSTOS NA GESTÃO DAS EMPRESAS DE PEQUENO PORTE - ANÁLISE EMPÍRICA NUMA INDÚSTRIA DE CONFECÇÕES
}

\section{THROUGHPUT COSTING AS PRACTICE OF COST MANAGEMENT OF SMALL BUSINESSES - AN EMPIRICAL ANALYSIS IN A CLOTHING INDUSTRY}

\author{
Laurindo Panucci-Filho ${ }^{1}$; Simone Bernardes Voese ${ }^{2}$ \\ ${ }^{1}$ Universidade Federal do Paraná - UFPR - Curitiba - Brasil \\ laurindopanucci@hotmail.com \\ ${ }^{2}$ Universidade Federal do Paraná - UFPR - Curitiba - Brasil \\ sbs1611@hotmail.com
}

\begin{abstract}
Resumo
A adoção de práticas de custos nas empresas tem sido tarefa árdua, tanto por parte dos gestores, que querem soluções precisas, como dos contadores, por vezes limitados a uma postura ortodoxa em relação ao desenvolvimento de novas ferramentas de gestão, ou por se resumir a alguns poucos procedimentos compatíveis com a sua posição hierárquica na cadeia decisória da empresa. Num primeiro momento, este trabalho discute conceitualmente os Métodos de Custeio Padrão, Custeio Variável e o Custeio Throughput, e, no segundo, uma variante dos demais métodos: o Custeio Throughput, que surge como uma fonte de relatórios eficazes e uma opção para as empresas de pequeno porte em fase inicial de vida, ou em estágios iniciais de um departamento de custos. $O$ objetivo geral de investigar se diante dos diversos métodos de custeio existentes, a empresa de pequeno porte também pode simplificar seus controles e continuar obtendo informações de qualidade, para uso interno, foi confirmado. A metodologia é o estudo de caso, desenvolvido numa indústria de pequeno porte, do setor de confecções. Os resultados finais respondem à questão de pesquisa proposta, assim como evidencia a sintonia entre os métodos de custeio abordados, proporcionando simplificação operacional das práticas de contabilidade de custos, com informações para decisão e controle, e confiabilidade na apropriação dos custos na empresa em estudo.
\end{abstract}

Palavras-chave: custeio padrão; custeio variável; custeio throughput.

\section{Introdução}

Ao abordar os aspectos da contabilidade de custos, o preponente da indagação intuitivamente investiga se o procedimento a ser adotado poderá retratar com fineza suas expectativas, logo valida a questão ou adiciona ingredientes que possam contemplar os objetivos específicos de decisão naquele momento. No contexto gestão empresarial esse é o dinamismo na área de custos desde quando foi concebido como parte do controle de gestão. 
A investigação das práticas de contabilidade de custos nas empresas constatou evolução desde o surgimento dos primeiros instrumentos de controle criados para avaliação de estoques e resultados até se tornar importante mecanismo de controle gerencial nos dias atuais, sendo objeto de profundas investigações no âmbito da gestão das empresas (MARTINS, 2008; ELDENBURG E WOLCOTT, 2007; BLOCHER et al., 2007).

A preocupação constante dos gestores de todos os níveis é o de manter a competitividade, encontrando na contabilidade de custos instrumentos adotados como práticas que proporcionam o balizamento das decisões com objetivo fim de posicionar o sucesso no grupo de empresas rentáveis e geradoras de resultados positivos (BLOCHER et al., 2007). Horngren, Datar e Foster (2004, p. 1) qualificam a contabilidade de custos como um fator essencial nas decisões exemplificando como a moderna contabilidade de custos é ampla: "A contabilidade de custos tem papel fundamental: desde fornecer informações para o planejamento de novos produtos até a avaliar o sucesso da mais recente campanha de marketing".

Conceitualmente, a contabilidade de custos para a gestão das empresas e na tomada de decisões tem importância comprovada. Porém, a informação se tornará útil se desenvolvida de maneira assertiva e em assimetria com as necessidades dos gestores de cada área, em contrário, tornará mais alguns números de pouca validade. Horngren, Datar e Foster $(2004$, p. 1) ao dizer que a "moderna contabilidade de custos fornece aos administradores as informações de que necessitam ao tomar decisões" transfere para os responsáveis dessa área o papel de compreender essa necessidade e procurar fornecer a informação mais precisa através das práticas de contabilidade de custos que mais reflitam a vontade dos gestores, Blocher et al. (2007, p. 3) resume o contexto geral da gerência eficiente dizendo que "a melhor informação é a chave do sucesso".

Eldenburg e Wolcott (2007, p. 9) relembram que as primeiras técnicas de contabilidade de custos surgiram no século 19, como uma necessidade gerencial e fins de controle, porém, no início atendiam apenas a determinados aspectos da gestão e "à medida que as empresas foram ficando maiores, também foi aumentando a necessidade mensurar, monitorar e motivar o desempenho". Assim, o desenvolvimento de pesquisas no campo da gestão de custos tomou maior impulso nas últimas décadas favorecido pelas recentes inovações tecnológicas, apresentando métodos de custeio mais eficazes, porém mais complexo de manuseio e implantação, exigindo pessoal melhor treinado e recursos financeiros para sua consolidação.

Diante do enunciado geral acima exposto, a pesquisa se desenvolverá tendo como questão a seguinte pergunta: as empresas de pequeno porte podem adotar a gestão de custos como práticas de controle interno, abrindo mão de sistemas complexos de custeamento? O objetivo inerente a esta questão é compilar argumentos existentes na utilização da contabilidade de custos para controle, e investigar se diante dos diversos métodos de custeio existentes, a empresa de pequeno porte 
também pode identificar o método que mais atende suas necessidades informacionais interna para fins de práticas de controle e gestão de custos.

Este estudo está estruturado em mais quatro tópicos. No tópico 2 é tratado do referencial teórico, abordando as diferentes finalidades de custos para decisão e seu emprego mais acentuado nas organizações, trata também dos conceitos do Método de Custeio-Padrão, do Método de Custeio Variável e Custeio Throughput, afim de tornar mais claro o relacionamento entre os métodos na aplicação do estudo de caso que vai ser tratado no tópico 4, onde o estudo se desenvolve numa empresa do setor de confecções como base para a aplicação do estudo e exemplificação da aplicação do Custeio Throughput como prática de contabilidade de custos. A metodologia do trabalho é descrita no tópico 3 e no tópico 5 descreve-se as conclusões da análise do estudo de caso, bem como a contribuição do estudo para a gestão das empresas de pequeno porte e as justificativas e explicativas da adoção de métodos de custeio menos aprimorados para o auxílio na gestão de custos e controle de empresas pouco complexas, como as empresas de pequeno porte com limitações na implantação de técnicas mais aprimoradas.

\section{Referencial Teórico}

A grande discussão no contexto dos custos "é como?" e "o que?" fazer para "controlar", "monitorar", "comparar", "reduzir", “avaliar", "reavaliar", "otimizar" são constante no rol de preocupações dos gestores nos variados níveis hierárquico das empresas. Em função da proposta do estudo, será discutidos os conceitos necessários para explicar o caso apresentado neste trabalho.

\subsection{Custos para diferentes finalidades}

No ambiente maior da gestão, a contabilidade de custos como parte da contabilidade gerencial, tem sido utilizada para diversas finalidades, voltadas para a gestão e o desempenho, Martins (2008, p. 23) ao descrever o processo de separação entre a contabilidade financeira e a de custos resume que "a Contabilidade de Custos nasceu da Contabilidade Financeira, quando da necessidade de avaliar estoques na indústria". Porém, a vasticidade de opções oferecidas pela gestão de custos exige uma delimitação específica de como utilizar a contabilidade e a gestão de custos, pois caso contrário, o risco do excesso de informação não servir pra muita coisa é maior. Nesta linha de pensamento, Eldenburg e Wolcott (2007, p. 555) acrescentam que "diferentes tipos de informações são úteis em diferentes contextos".

Numa empresa industrial, os custos e os métodos adotados servem, dentre muitos contextos, para avaliar estoques. Porém, ainda referindo-se ao método de custeio para fins de avaliação de estoques, Eldenburg e Wolcott $(2007$, p. 555) alerta aos gestores de custos que "não existe uma única medida de avaliação de estoques e de custos dos produtos vendidos que seja a melhor para 
todas as situações", atribuem ao contador a responsabilidade de interagir com a administração afim de identificar quais as ações a serem tomadas, afim de adotar as melhores práticas.

Para Eldenburg e Wolcott (2007, p. 555) "a informatização dos sistemas contábeis hoje permite aos contadores calcular facilmente os custos segundo diversas formas", Martins (2008, p. 22) permite analisar este aspecto ao tratar da modernidade contábil, "a Contabilidade mais moderna vem criando sistemas de informações que permitem melhor gerenciamento de Custos, com base neste enfoque", ficando intrínseco para reflexão a inferência que o contador conta com apoio de outra área, a da informática para auxiliar no desenvolvimento do seu trabalho. Neste caso, o conhecimento multidisciplinar do contador poderá seu útil, uma vez que é possível tratar as informações para cada usuário com a mesma fonte de dados, Eldenburg e Wolcott (2007, p. 575) “antes que as novas tecnologias tornassem relativamente fácil a tarefa de produzir diversos relatório diferentes a partir de uma mesma base de dados, a maioria das organizações implementava sistemas voltados principalmente para atender às normas da contabilização financeira e tributária”.

Levando-se em conta o leque de opções que a contabilidade de custos oferece, dentre eles a avaliação dos estoques, a gestão estratégica dos custos e a tomada de decisões diversas, nem sempre esses princípios são tomados como verdade em referência à gestão. Em muitos casos os gestores estão mais preocupados com a avaliação do que com o controle, característica marcante das pequenas e médias empresas em estágio inicial de vida.

A avaliação se torna essencial no julgamento prévio quando se inicia a implantação da área de custos, pois exigem pouca formalidade e rigidez de procedimentos, comparando-se com os métodos de controle divulgados recentemente. Optando pelo desenvolvimento de ferramentas que levem a adoção de práticas dessa característica, é evidente que, controlar custos para obter o valor dos produtos acabados contendo todos os gastos incorridos é tarefa exaustiva, mesmo contando com o auxílio da tecnologia da informação e de contadores treinados. Muitos gestores aderem à praticas menos complexas, mas que satisfazem suas decisões no momento.

Estudos anteriores revelam que a adoção de mais de uma técnica conjugada podem resultar ação estratégica de controle de custos. Bezerra et al. (2007, p. 77) ao estudar a adoção do custeio baseado em atividades (Activity-Based Costing - ABC) por um banco relata que uma característica adotada na metodologia de implantação do método foi a "opção da não distribuição completa dos custos", somente os custos que puderem ser identificados por algum critério razoável é que foram alocados à atividade, "os demais custos compuseram um grupo de custos que foi absorvido pela corporação como um todo. Trabalhou-se assim com um misto entre Custeio Variável e ABC".

Kaspczak e Scandelari (2007, p. 125;132) estudaram as práticas de administração de custos na cidade de Ponta Grossa, Estado do Paraná e identificaram que falta tecnologia adequada para a implantação de sistemas de custeio, porém as que conseguem desenvolver algum controle de custos 
é mais para a "formação de preço de seus produtos" e "controlar e reduzir seus custos". O estudo conclui ainda que falta conhecimento de custos por parte dos administradores daquelas empresas da amostra, o que se houvesse conhecimento, "estes poderiam identificar melhor os possíveis desperdício em seu processo produtivo e, como conseqüência, poderiam oferecer preços mais competitivos ao mercado consumidor".

\subsection{Custo-padrão}

A adoção do Custo-Padrão como instrumento de predeterminação dos custos por empresas de porte e segmentos variados se deve à compatibilidade entre expectativas e resultados que o método oferece, Fellipini (2005, p. 117) identificou que essa preocupação existia nas empresas que foram objeto de sua pesquisa, $81 \%$ da amostra "afirmam efetuar o comparativo dos objetivos versus os resultados". Eldenburg e Wolcott (2007, p. 234) relatam essa compatibilidade ao escrever que o “Custo-Padrão é aquele que os gestores esperam que aconteça quando os bens e serviços são produzidos sob as normas técnicas do plano operacional”, Blocher et al. (2007, p. 455) estabelece que o "Custo-Padrão é um custo que cuidadosamente predeterminado que uma empresa ou uma organização estabelece para sua operação", VanDerbeck e Nagy (2001, p. 35) desenvolvem que "Custos-Padrões seriam incorridos sob condições de operação eficientes e são previstos antes do processo de manufatura começar".

As definições apresentadas pelos diferentes autores asseguram que existe forte cumplicidade entre o estabelecimento prévio e a efetiva execução das operações, servindo de base para comparação com o Real. Martins (2008, p. 316) aduz funcionalidade mais emblemática quando relaciona o Custo-Padrão com o "planejamento e controle dos custos", funcionalidade concomitante com a necessidade dos gestores das mais diversas áreas.

A aceitação do Custo-Padrão se deve ao fato da objetividade que o método trabalha, pois ao se estabelecer previamente as ações futuras, vai funcionando como uma seta a ser seguida, trazendo maior confiança aos tomadores das decisões. Esta particularidade do método é que faz o CustoPadrão ser aceito na maioria das empresas que iniciam a implantação de um sistema de custos, induzindo ao entendimento de simplicidade. Martins (2008, p. 317) alerta que o Custo-Padrão não é uma forma de simplificar os procedimentos da empresa, mas agregar maior confiabilidade nas decisões que vai sendo medido conforme é comprado com o real e o que aconteceu de fato, após a determinação do objetivo fim da empresa.

Na demonstração do objetivo principal quanto a adoção do Custo-Padrão, Martins (2008, p. 316) alerta que "o Custo-Padrão não é uma outra forma, método ou critério de contabilização de custos (como Absorção ou Variável), mas sim uma técnica auxiliar”, necessitando de um outro instrumento para atuar como elemento central das decisões, surgindo a necessidade de outras 
técnicas mais propícias de comparabilidade operando paralelamente ao Padrão. Mesmo entendimento é o de VanDerbeck e Nagy (2001, p. 35) quando descrevem que "um sistema de contabilidade de Custo-Padrão, que não é um terceiro sistema, [...] é projetado para fornecer uma medida que ajudará a administração a tomar decisões com relação à eficiência das operações”.

$\mathrm{Na}$ releitura de Martins (2008, p. 315-321), algumas características essenciais do CustoPadrão podem ser elencadas, como: (a) base para comparabilidade; (b) necessita de um bom sistema de custos operando paralelamente; (c) coadjuvante no sistema de custeio, atuando em conjunto com outro método pré-definido; (d) é eficaz quando operado em conjunto com o custo real, que pode ser obtido através do método de custeio pré-definido; (e) não é correto encarar como meio de simplificar a vida da empresa, pois conforme definição de eficácia, exige a comparação com outro método de custeio, tornando trabalhosa a comparabilidade; (f) sua implantação é mais bem sucedida em empresas onde já existe a noção de custos; (g) atua sobre os indivíduos de maneira psicológica, despertando satisfação ou insatisfação sobre o método; (h) exige seriedade na condução das análises e ações provenientes da comparabilidade; (i) torna a empresa comprometida com o registro e o controle dos valores reais e das unidades de medida adotados no sistema de custo.

Com referência ao exposto, o Custo-Padrão tem como principal elemento promover a unanimidade, seja nos gastos, na produção, no tratamento e interpretação das informações pelos gestores, promovem as decisões e mesmo uma planificação no entendimento dos objetivos estabelecidos pela direção da empresa.

Ao estabelecer o "padrão", torna-se mais sutil o entendimento dos requisitos necessários para o alcance dos objetivos gerais, que deveria ser conhecido por todos os elementos da empresa. Martins (2008, p. 317) conceitua que "o Padrão é uma base de comparação", para VanDerbeck e Nagy (2001, p. 327) o estabelecimento do padrão, serve ainda para comparar e promover o bom desempenho: "Um padrão é uma norma com a qual o desempenho real pode ser mantido", Blocher et al. (2007, p. 457) ao estabelecer a importância de padrões, ressalta que não existe um modelo estabelecido a todos os casos, e cada empresa precisa identificar os seus propósitos, e que servirão de base para ações futuras, neste caso estabelece que "o padrão mais adequado para uma empresa é aquele que ajuda a atingir seus objetivos estratégicos”.

\subsection{Custo variável}

O Método de Custo Variável apropria somente dos custos variáveis aos produtos, ficando os custos fixos como despesas do período, no resultado do exercício (MARTINS, 2008). Ponte, Riccio e Lustosa (1999) relatam que o "custeio variável é uma sistemática de custeamento em que somente os custos variáveis, quer diretos ou indiretos, são apropriados aos produtos". Contudo, hodierno, as definições encontradas fazem a mesma explanação. 
Martins (2008, p. 197-204) descreve que este método nasceu da comparação com outros métodos, quando se verificaram riscos e desvantagens da apropriação dos custos fixos aos produtos. Esses custos foram listados como decorrentes das necessidades de se manter e colocar em dia as operações da empresa em funcionamento, estando pouco vinculados aos produtos, especificamente. VanDerbeck e Nagy (2001, p. 407) compartilham desse entendimento relatando que "o custo de um produto manufaturado inclui apenas os custos que variam diretamente com o volume [...] porque apenas os custos variáveis de manufatura são atribuídos ao produto, enquanto CIF (Custo Indireto Fixo) são classificados como custo do período e debitados totalmente no período no qual os custos fixos foram incorridos". Blocher et al. (2007, p. 614) chama esse método de custeio variável "porque separa os custos fixos e variáveis [...] os custos variáveis são incluídos na determinação do custo de vendas e da margem de contribuição".

Na definição de Horngren, Datar e Foster (2004, p. 277), “o custeio variável é um método de custeio em que apenas os custos de materiais diretos são incluídos como custo do produto", e tratam os custos fixos como sendo do período. Horngren, Sundem, Stratton (2004, p. 498) destacam que a crescente utilização da contabilidade de custos para tomada de decisões internas da empresa, "tem levado ao crescente uso do custeio variável para propósitos de relatório interno".

Os métodos de custeios procuram precificar os estoques representando os gastos incorridos para transformar os materiais em produtos acabados. O Método de Custo Variável oferece esse recurso satisfazendo as necessidades dos gestores em momento de avaliação dos estoques.

A análise da margem de contribuição na mensuração de desempenho e análise de custos são instrumentos que validam o Método de Custo Variável, importante para decisões gerenciais (HORNGREN; SUNDEM; STRATTON, 2004).

\subsection{Custeio Throughput}

Este tópico do trabalho tem o propósito de elucidar parte da questão que motivou o desenvolvimento desta pesquisa. Inicialmente a pergunta a ser investigada é abordada como a mesma dos diversos usuários da informação contábil gerencial, e que não tem à disposição as modernas técnicas de gerenciamento, por limitações peculiares, mas neste caso a restrição pode estar no universo da empresa de pequeno porte. Eldenburg e Wolcott (2007, p. 572) descrevem que o custeio throughput foi "desenvolvido na década de 1980 como parte da Teoria das Restrições" tornando-se "popular para fins de relatórios internos em empresas norte-americanas e européias".

Delimitando o estudo do caso à aplicação do método, serão dispensados maiores aprofundamentos sobre o assunto da teoria das restrições, pois abrangem aspectos teóricos mais distantes do propósito desta pesquisa. O intuito é estabelecer mecanismos de evidenciação da informação, de maneira prática, objetiva e que o gestor utilize o instrumento da informação de 
maneira satisfatória para o momento. No entendimento da pesquisa, o termo "Contabilidade de Ganhos" faz referência ao termo "Custeio Throughput".

Com relação ao tempo, no delimitar da contabilidade ganhos, Eldenburg e Wolcott (2007, p. 575) fazem comparações com os diversos métodos de custeio, evidenciam que o custeio por absorção é freqüentemente utilizado para os usuários externos, pois está conceitualmente preocupado na confrontação entre as receitas e as despesas, sendo foco do método a evidenciação no logo prazo. As demonstrações elaboradas com base no custeio variável são mais utilizadas avaliação do desempenho de uma divisão ou de um gerente, e de certa forma, utilizada por ambos os usuários externos e internos.

No caso da contabilidade de ganhos, "as demonstrações de resultados feitas segundo o custeio throughput ajudam os gerentes a determinar qual será a utilização mais eficiente dos recursos da empresa a curto prazo". Essa distinção entre os métodos está relacionada ao que se consideram como custos nos diferentes métodos, pois ao alocar custos aos produtos a contabilidade evidencia informações que podem influenciar as decisões.

Eldenburg e Wolcott (2007, p. 574) diferenciam os métodos relatando que os "métodos contábeis diferem em relação ao que se consideram custos dos produtos, os quais, para o custeio por absorção, são todos os custos de produção; para o custeio variável, somente os custos variáveis de produção; e para o custeio throughput, somente os custos dos materiais diretos". A Tabela 1 resume as características comuns aos dois métodos de custeio adotados no estudo.

Observando o quadro comparativo, as semelhanças entre os métodos são evidentes. Ambos são aceitos apensas para decisões internas e não operam com rateios, e os dois métodos consideram os materiais como custos do estoque, embora o custeio variável atribua também o valor da mão-deobra direta.

O custeio throughput considera custo dos produtos vendidos somente os materiais empregados e as despesas do período, diferença a ser considerada frente ao método de custeio variável, pois caso a empresa não efetue vendas num período o resultado tende a ser mais negativo. No entanto, a particularidade do método precisa ser considerada na adoção para fins específicos da gestão.

Tabela 1 - Comparação Entre o Custeio Variável e o Custeio Throughput

\begin{tabular}{|c|c|}
\hline CUSTEIO VARIÁVEL & CUSTEIO THROUGHPUT \\
\hline Útil para decisões internas & Útil para decisões internas \\
\hline $\begin{array}{l}\text { Existem custos fixos e variáveis e despesas fixas e } \\
\text { variáveis. }\end{array}$ & $\begin{array}{l}\text { Existem custos totalmente variáveis e não totalmente } \\
\text { variáveis. Os custos não totalmente variáveis são chamados } \\
\text { de despesas. }\end{array}$ \\
\hline Não existem rateios. & Não existem rateios. \\
\hline $\begin{array}{l}\text { Útil para avaliação de desempenho e nos processos } \\
\text { decisórios internos }\end{array}$ & $\begin{array}{l}\text { Útil nos processo decisórios envolvendo a capacidade de } \\
\text { curto prazo; faz os gerentes concentrarem a atenção na } \\
\text { redução dos custos da mão de obra e dos custos indiretos de }\end{array}$ \\
\hline
\end{tabular}




\begin{tabular}{|c|c|}
\hline & $\begin{array}{l}\text { fabricação, que são considerados custos operacionais e não } \\
\text { custos dos produtos (estoques). }\end{array}$ \\
\hline $\begin{array}{l}\text { Os custos do materiais diretos e da mão-de-obra direta } \\
\text { são atribuídos aos estoques. }\end{array}$ & Somente os custos dos materiais são atribuídos aos estoques \\
\hline $\begin{array}{l}\text { Os custos indiretos fixos de fabricação são contabilizados } \\
\text { como despesas do período. Os custos indiretos variáveis } \\
\text { de fabricação são alocados aos estoques }\end{array}$ & $\begin{array}{l}\text { Os custos da mão-de-obra direta, os custos indiretos fixos e } \\
\text { variáveis de fabricação e todos os demais custos são } \\
\text { contabilizados como despesas operacionais, e fazem parte } \\
\text { do custo do período }\end{array}$ \\
\hline $\begin{array}{l}\text { Os custos de administração e de vendas são divididos } \\
\text { entre fixos e variáveis e contabilizados como despesas do } \\
\text { período }\end{array}$ & $\begin{array}{l}\text { Os custos de administração e de vendas são contabilizados } \\
\text { como despesas operacionais no custo do período }\end{array}$ \\
\hline $\begin{array}{l}\text { Os custos dos estoques (somente os custos variáveis de } \\
\text { produção) somente são contabilizados após as unidades } \\
\text { serem vendidas e são avaliados pelos custos variáveis }\end{array}$ & $\begin{array}{l}\text { Os custos dos estoques (somente os dos materiais diretos) } \\
\text { somente são contabilizados após as unidades serem } \\
\text { vendidas e são avaliados pelos custos totalmente variáveis }\end{array}$ \\
\hline $\begin{array}{l}\text { As receitas de vendas, deduzidos os custos dos produtos } \\
\text { vendidos e as despesas variáveis, representam a margem } \\
\text { de contribuição. }\end{array}$ & $\begin{array}{l}\text { As receitas de vendas, deduzidos os custos dos produtos } \\
\text { vendidos, representam o ganho. }\end{array}$ \\
\hline $\begin{array}{l}\text { O lucro é o resultado da margem de contribuição } \\
\text { subtraídas as despesas e os custos fixos. }\end{array}$ & O lucro é o \\
\hline
\end{tabular}
Fonte: Adaptado de Eldenburg e Wolcott (2007, p. 574) e Ponte, Riccio e Lustosa (1999)

\section{Procedimento metodológico}

$\mathrm{Na}$ definição do procedimento metodológico, o pesquisador procura definir quais os descritores do planejamento da pesquisa são mais acentuados. Frente a esse entendimento, Cooper e Schindler (2003, p. 128) relatam "que existem diversos modelos diferentes, mas infelizmente, nenhum sistema de classificação único define todas as variações que devem ser consideradas”, e apresenta alguns descritores, que combinados entre si, contribuem para a elaboração do planejamento de pesquisa. Richardson (2007, p. 15) também discute a imperfeição na definição do planejamento de pesquisa quando escreve que "não existe uma fórmula mágica e única para realizar uma pesquisa ideal" e procurando balizar os objetivos da pesquisa com os propósitos acrescenta que "é melhor ter um trabalho de pesquisa imperfeito a não ter trabalho nenhum".

Porém, Cooper e Schindler (2003, p. 142) alertam que mesmo não sendo uma tarefa fácil o estabelecimento da classificação da pesquisa adverte que é preciso planejar, pois "um planejamento de pesquisa é a estratégia para um estudo e plano através do qual a estratégia deve ser desenvolvida".

Os descritores propostos por Cooper e Schindler (2003, p. 129), adotados nesta pesquisa são os seguintes: 1. Grau de cristalização de pesquisa é um estudo formal, porque segue procedimentos na coleta de dados e especifica a fonte, procurando responder a uma questão de pesquisa; 2. Objetivo do estudo é a combinação entre o descritivo e causal, porque procura-se uma alternativa para a prática de custos nas empresas de pequeno porte, comparando métodos e demonstrando alternativas; 3. A dimensão de tempo da pesquisa é o transversal, porque considera um espaço de tempo ou uma data específica; 4 . O escopo do estudo é o de caso, porque contextualiza um evento da vida real no qual a intervenção ocorreu. 
Diante dessas definições e do objetivo proposto na questão, a pesquisa tem como característica o Estudo de Caso. O desenvolvimento da pesquisa e a coleta de dados serão objeto de profundidade no entendimento e interpretação do caso, com o tratamento dos dados afim de atender ao que a pesquisa se propõe a investigar. Os dados do caso foram coletados e tratados com o propósito de promover uma resposta conclusiva acerca da questão norteadora desta pesquisa.

\section{Resultados e análises}

Um dos problemas evidentes que a contabilidade de custos procura resolver ao adotar métodos de custeio específico refere-se à avaliação correta dos estoques. Porém, como tratado no referencial teórico, a empresa de pequeno porte não possui total controle dos seus custos e não dispõe de instrumentos de controle elaborados, como os corretamente exigidos pela moderna gestão de custos. Sendo alvo, freqüentemente de críticas principalmente pelo gestor que necessita de informação, atribuindo à contabilidade de custos obsolência ou incapacidade de evidenciar os problemas que mais freqüentemente elevam o custo dos produtos, e os auxiliem na tarefa de monitorar o desempenho.

Uma das incertezas na elaboração do preço de vendas reside na fixação dos custos e despesas indiretas. Em muitos casos esse valor pode representar a diferença nas variações corridas no período, entre o padrão e o realizado. Desta forma, opera-se num mecanismo de evidenciar este valor frente as práticas de custos delimitadas neste trabalho.

Procurando oferecer uma alternativa para essa lacuna na gestão de custos, o estudo tem como tarefa principal oferecer uma opção de relatório gerencial de custos como adoção de práticas de custos por empresas de pequeno porte, atualmente no estágio inicial da implantação dessa área.

As informações disponibilizadas pela empresa são provenientes de uma DRE Demonstração de Resultado do Exercício, encerrado para fins de avaliação financeira todo mês. Um funcionário da empresa transporta todos os pagamentos numa planilha, antes do envio ao escritório de contabilidade. A planilha está estruturada de acordo com a disposição da legislação e separada em contas de despesa nos agrupamentos representativos. Tomou-se esta base de dados, e uma revisão foi feita, a fim de identificar e excluir pagamentos a fornecedores de materiais diretos, servindo para o estudo em desenvolvimento.

Orientando-se pelo método do custeio padrão, o primeiro passo foi uma investigação criteriosa, procurando identificar o valor das despesas que serviriam de média para o período tomado como base. Atribuiu-se valores para cada conta da DRE, obtendo-se o valor padrão das contas. Obtendo-se o valor considerado pelo custeio throughput, os custos do período.

Concomitante a isso, foi necessário conhecer algumas particularidades do setor de produção. Identificou-se que o gestor principal da empresa considerava que o número de costureiras era 
suficiente para manter a fábrica funcionando, e que os demais funcionários - auxiliares de costura, arrematadeiras, mecânicos, e todos os outros funcionários da área produtiva e da área administrativa eram necessários porque existia um número de costureiras servindo de base para a manutenção de toda a estrutura da empresa. Em aspectos gerais, se reduzisse o número de costureiras, o trabalho reduziria e as outras atividades poder-se-ia reduzir pessoal.

Outro entendimento desenvolvido foi o de que os funcionários das outras atividades poderiam ser multifuncionais, caso sobrasse tempo no arremate, por exemplo, o pessoal ocioso poderia se ocupar de alguma outra função que estivesse necessitando de mais pessoal. Esse conceito é concomitante com o conceito de tempo da peça, medido em minutos. Esse foi o "gargalo" identificado na produção, e as ações serão no sentido de neutralizar esse gargalo.

$\mathrm{Na}$ indústria de confecções toda peça é cronometrada e delimitado o tempo padrão de produção, ou seja, cada peça tem um tempo definido para cada tarefa: corte, costura, acabamento, etc. Na elaboração da peça piloto (a peça que serve para definir os materiais, o tempo e caracterização final), esse tempo é padrão. Cronometra-se o tempo que faz parte da ficha técnica da peça. Esse tempo em conjunto com os materiais e serviços fazem parte do custo da peça pronta. A empresa adota 4 dias de trabalho com 9 horas e um dia (sexta-feira), com 8 horas. Nessa matemática os dias não trabalham com fração de minutos e contempla as 44 horas semanais, sem precisar trabalhar no sábado.

De posse desses dados é possível definir o escopo do trabalho prático, que necessariamente passará por três etapas. a) definição do tempo médio na semana de trabalho por uma costureira; b) definição do tempo médio no mês pelas costureira da fábrica; c) definição do valor do tempo padrão trabalhado por uma costureira no mês. Como padrão, o tempo da peça é trabalhado em minutos. Portanto, todas as unidades de medida precisam estar na grandeza do minuto, ou seja, precisamos transformar horas em minutos e o valor dos custos do período em fração de horas, para conhecer quanto vai custar a peça acabada.

Uma costureira trabalhando as 44 horas da semana, é capaz de trabalhar 2.640 minutos por semana, ou 528 minutos por dias. Este passa a ser o tempo padrão de trabalho de uma costureira, o restante dos cálculos é multiplicação desse valor pelo número elementos trabalhado no dia. $\mathrm{Na}$ Figura 1 é possível demonstrar o cálculo a ser usado no encerramento do período em comparação com o real.

Figura 1 - Tempo Médio/Semana

\section{A) Tempo Médio/Semana}

\begin{tabular}{|c|c|c|c|c|c|}
\hline & & & Horas & $\begin{array}{c}\text { Minutos } \\
\text { Hora }\end{array}$ & $\begin{array}{c}\text { Minutos } \\
\text { Total }\end{array}$ \\
\hline $\mathrm{N}^{\mathrm{o}}$ de dias/Semana: & 4,00 & Tempo trabalhado no dia: & 9,00 & 60,00 & $2.160,00$ \\
\hline $\mathrm{N}^{\mathrm{o}}$ de dias/Semana: & 1,00 & Tempo trabalhado no dia: & 8,00 & 60,00 & 480,00 \\
\hline
\end{tabular}




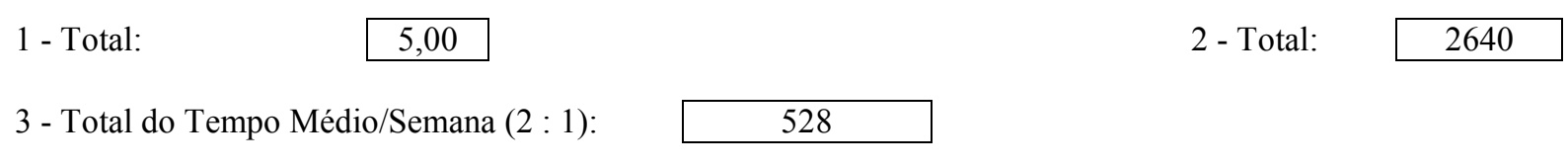

Fonte: Dados da pesquisa

A Figura 2 demonstra a capacidade total da fábrica no mês, esta avaliação está sendo medida com base na mão-de-obra direta à disposição da fábrica. Entende-se que existe maquinário suficiente para a demanda da fábrica e supõe se que a fábrica opera na sua capacidade máxima durante todo o mês. O tempo total é de 1.267.200 minutos que as 120 costureiras vão precisar para desenvolver a produtividade da fábrica.

Figura 2 - Tempo Médio/Mês

B) Tempo Médio/Mês:

4 - $\mathrm{N}^{\mathrm{o}}$ de empregados na montagem da peça:

5 - Dias úteis/mês:

20

6 - Total Tempo Médio/Mês (3 x 4 x 5):

1.267 .200

Fonte: Dados da Pesquisa

Na Figura 3 estão resumidas informações necessárias para as decisões requeridas no início do estudo do caso, o valor a ser fixado como padrão para os custos e despesas variáveis.

Figura 3 - Valor do Tempo Padrão

C) Valor do Tempo Padrão
7 - Eficiência (\%):
8 - Custo de Transformação (desp. Fixas/mês atual):
9 - Total do Tempo Produtivos/mês (6 x 7).............
10 - Valor do Tempo Padrão $(8: 9)$.........................

Fonte: Dados da Pesquisa

O valor do custo de transformação é o mesmo do levantado na fixação do custo e despesas padrão, é o valor necessário para a empresa manter-se em funcionamento e garantir os elementos de custos aplicados na produção. Um aspecto a ser considerado neste cálculo é que a eficiência das costureiras decai em 15\% depois que a peça piloto fica pronta, ou seja, uma peça piloto leva $15 \%$ menos tempo para ficar pronta que uma peça na linha de produção, por causa dessa distorção, considerará a eficiência da produção em 85\% do Total de Tempo Médio para as 120 costureiras.

Frente a esse cálculo, o tempo padrão a necessariamente será de R\$ 0,6826. Critério semelhante foi encontrado por Fillippini (2005, p. 107) "[...]calculam os CI, dividem pelos minutos trabalhados e repassam para o produto de acordo com o tempo gasto pelos mesmos". Como o tempo 
padrão da peça é composto por minutos, esse valor será a multiplicação do tempo padrão da peça, vezes o tempo padrão em Reais.

Conhecendo-se o tempo padrão da peça, torna-se mais preciso a atribuição de custos à peça. Esta precisão, dentre outras informações relevantes, tem-se o preço de venda mais assertivo, e é possível comparar valores com os similares no mercado.

Na Tabela 2 é possível compreender a forma expositiva de onde usar o Valor do Tempo Padrão. Os custos variáveis - matéria-prima e aviamentos, são conhecidos pois são identificados na peça, bem como a medida e o preço de cada componente.

Tabela 2 - Composição do Produto

\begin{tabular}{|c|c|c|c|c|c|c|c|}
\hline \multicolumn{2}{|c|}{ Matéria - Prima } & \multicolumn{2}{|c|}{\begin{tabular}{l|c}
$s$ & $\begin{array}{c}\text { Materiais } \\
\text { Diretos } \\
\text { /Totais }\end{array}$ \\
\end{tabular}} & $\begin{array}{c}\text { Materiais } \\
\text { Diretos } \\
\text { /Peça } \\
\end{array}$ & $\begin{array}{l}\text { Custo- } \\
\text { Padrão }\end{array}$ & $\begin{array}{c}\text { Tempo } \\
\text { Padrão da } \\
\text { Peça } \\
\end{array}$ & $\begin{array}{l}\text { Custo } \\
\text { Total }\end{array}$ \\
\hline CRON. & Tempo peça & & & & R\$ 0,68 & 20,83/Min & 14,1644 \\
\hline TEC. & Tecido & 1 & $0,187368 \mathrm{Kg}$ & $0,187 / \mathrm{Pç}$ & $\mathrm{R} \$ 34,37$ & & 6,42719 \\
\hline AVIA. & Etiq. de Composição & 1 & $1,000000 \mathrm{Un}$ & $1,000 / \mathrm{Pç}$ & $\mathrm{R} \$ 0,01$ & & 0,01000 \\
\hline AVIA. & Tag & 1 & $1,000000 \mathrm{Un}$ & $1,000 / \mathrm{Pç}$ & $\mathrm{R} \$ 0,01$ & & 0,01000 \\
\hline AVIA. & Etiqueta bordada & 1 & $1,000000 \mathrm{Un}$ & $1,000 / \mathrm{Pç}$ & $\mathrm{R} \$ 0,05$ & & 0,05000 \\
\hline AVIA. & Renda & 1 & $0,840000 \mathrm{Kg}$ & $0,840 / \mathrm{Pç}$ & $\mathrm{R} \$ 3,51$ & & 2,94840 \\
\hline AVIA. & Elástico de viés & 1 & $0,020000 \mathrm{Kg}$ & $0,020 / \mathrm{Pç}$ & $\mathrm{R} \$ 0,46$ & & 0,00920 \\
\hline AVIA. & Malha & 1 & $0,003000 \mathrm{Kg}$ & $0,003 / \mathrm{Pç}$ & $\mathrm{R} \$ 18,44$ & & 0,05532 \\
\hline AVIA. & Bojo & 1 & $1,000000 \mathrm{Un}$ & $1,000 / \mathrm{Pç}$ & $\mathrm{R} \$ 1,91$ & & 1,91000 \\
\hline AVIA. & Fita de Cetim & 1 & $1,260000 \mathrm{Kg}$ & $1,260 / \mathrm{Pç}$ & $\mathrm{R} \$ 0,16$ & & 0,20160 \\
\hline AVIA. & Caixa & 1 & $1,000000 \mathrm{Un}$ & $1,000 / \mathrm{Pç}$ & $\mathrm{R} \$ 1,90$ & & 1,90000 \\
\hline AVIA. & Argola Reguladora & 1 & $4,000000 \mathrm{Un}$ & $4,000 / \mathrm{Pç}$ & $\mathrm{R} \$ 0,02$ & & 0,08000 \\
\hline AVIA. & Bijuteria & 1 & $1,000000 \mathrm{Un}$ & $1,000 / \mathrm{Pç}$ & $\mathrm{R} \$ 3,70$ & & 3,70000 \\
\hline AVIA. & Linha & 1 & $1,000000 \mathrm{Un}$ & $1,000 / \mathrm{Pç}$ & $\mathrm{R} \$ 0,15$ & & 0,15000 \\
\hline \multicolumn{7}{|c|}{ 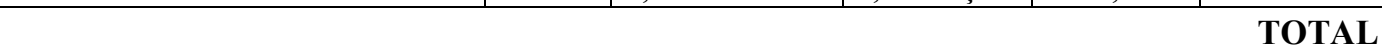 } & 31,16110 \\
\hline
\end{tabular}

Fonte: Dados da Pesquisa

O tempo da peça também foi definido na criação da peça, sabe-se o tempo necessário para o percurso de todos os processos até a finalização em produto acabado. Neste caso, o padrão dos custos e de pesas indiretas fixas e varáveis referentes ao tempo da peça permaneceu desconhecido até a adoção do método de custeio adequado - a combinação entre o custeio padrão, custeio variável e o custeio throughput.

Neste estágio é possível estabelecer com maior precisão o custo de determinado produto. Com o valor dos custos variáveis e o estabelecimento de um padrão para os custos fixos, a possibilidade de acerto tornou-se maior. É necessário ainda monitorar os custos, tanto os fixo quanto os variáveis afim de não se distanciarem demasiadamente do que se estabeleceu como padrão. Os critérios desse monitoramento deverão ser os mesmos estabelecidos para o padrão, porém, as variações deverão estar sendo esclarecidos e corrigidos, validando a questão de pesquisa, pois mesmo sendo pouco complexo a informação gerado por essa prática poderá contribuir substancialmente para o controle de custos na empresa. 


\section{Conclusões}

No exposto, com a adoção do Custeio Throughput como prática de contabilidade de custos é possível conhecer uma etapa do ciclo de custeamento. Em muitos casos, como o das empresas de pequeno porte onde o controle e a adoção de métodos de custeio mais refinados é inexistente, pode contribuir como um direcionador nas decisões.

Não entrando no mérito da discussão de qual método é mais eficaz na gestão de custos, o método de custeio padrão, bem como o método de custeio variável são passíveis de imperfeições e as criticas aos métodos são freqüentes, porém sua contribuição à gestão de custos é inegável, respaldando com mais segurança as decisões de quem adotou.

$\mathrm{Na}$ concepção de aproximar o que se julga não muito perfeito às necessidades iminentes dos gestores, que se sentem desprotegidos pela contabilidade de custos, fluiu esta pesquisa no intento de identificar o método de custeio que mais atende suas necessidades de gestão, proporcionando uma ferramenta útil para os gestores. O método de custeio throughput, mesmo sendo radical ao tratar do custeio de produção, tende a ser um instrumento eficaz como práticas de custos em empresas de pequeno porte, pois seu princípio básico reside na gestão interna de custeamento, fornecendo informação essencial para a gestão de curto prazo, e nesta particularidade reside fator substancial que buscam os gestores na implantação inicial de uma área de custos para decisão.

Importante salientar que ao adotar um método de custeio, este tende a ser flexível e incorporar mudanças, pois com o passar do tempo novos processos se desenvolvem, maior complexidade agrega valor ao produto e frente a essa reflexão, o gestor tem condições de ir migrando para outros métodos mais eficazes para aquele momento. Eldenburg e Wolcott (2007) foram sucintas ao evidenciar que a tecnologia é uma grande aliada da gestão de custos, porém sabese que no início de toda atividade paralelamente à particularidade das empresas de pequeno porte, o começo é fixado na redução de gasto e no curto prazo.

No caso deste estudo, a adoção do Método do Custo-Padrão, combinado com o Método do Custo Variável e o Custeio Throughput como práticas de contabilidade de custos e relatório gerencial é eficaz no controle interno, tendo em vista a necessidade de informação e a decisão que está sendo tomada no contexto da empresa de pequeno porte, uma vez que a complexidade das operações não demandam aprimoramento das técnicas gerenciais e de custos. O gestor quer saber se as suas ações representam coerência nas realizações futuras e a realização do planejamento não se traduzirá em divergências substanciais no futuro.

O fato relevante que se obtém na adoção desta prática é que a empresa pode dispensar cálculos mais aprimorados para a apuração do seu custo final, comparando com o realizado em determinado período, aufere validade no planejamento inicial estabelecido como padrão e têm um 
índice para fins de monitoramento dos custos e despesas indiretas fixas e variáveis. Pressupondo que o registro efetivo dos custos e despesas classificados nesta terminologia passam a ser controláveis e conhecidos pelo gestor, pode-se considerar elucidado a dúvida permanente da participação dos custos não identificados diretamente ao produto e se eles estão ocorrendo além do ideal para determinada empresa.

O controle é mais efetivo, pois a uniformidade de medida possibilita a visão macro da produção. Cada unidade produzida é responsável pela manutenção de gastos indiretos a ela e este fator dispensa critérios de rateios arbitrários de alocações. Em parte, considera-se ideal para a adoção em empresas onde o volume de produção e de operações é reduzido, e mais propício ao controle de empresas onde não se demanda de instrumentos mais aprimorados, como pessoal, recursos financeiros na implementação de sofisticados métodos de custeamento e gerenciamento.

É vidente que a canalização de algo complexamente aprimorado como os métodos de custeio, demandam prudência na sua adoção, pois tende a ser direcionador das decisões e influenciável na gestão das organizações e encontrado elemento que dê segurança ao gestor responsável pelas decisões, já pode-se considerar cumpridor do seu papel essencial: auxiliar na gestão e no controle das organizações.

\begin{abstract}
The adoption of practices of costs in companies has been challenging, both for managers who want accurate solution, as the accountants, limited to an orthodox stance in relation to the development of new management tools, either because they boil down to a few procedures compatible with its position hierarchical in the chain of decision-making enterprise. At first, this paper discusses conceptually the methods Standard Costing, Variable Costing, and Throughput Costing, and, at second, a variant of the other methods: the Throughput Costing, which appears as a source of effective reports and an option for firms small in early life, or in the early stages of a cost department. The overall goal to investigate if before the different costing methods exist, the small business can also simplify your controls and continue to get quality information for internal use, was confirmed. The methodology is case study, developed a small industry, of the clothing sector. The final result responded the question of proposed research, as well as showing the harmony between the costing methods discussed, providing operational simplification of cost accounting practices, with information for decision and control, reliability and ownership costs in the company under study.
\end{abstract}

Key-words: standard costing, variable costing, throughput costing.

\title{
Referências
}

BEZERRA,F. A; NASCIMENTO, D. T; BOFF, M. L; ISHIKURA, E. R. Custeio das modalidades de consumo de recursos: um estudo de caso sobre $\mathrm{ABC}$ em bancos. Revista Universo Contábil, Blumenau, v. 3, n. 3, p. 71-86, set./dez. 2007.

BLOCHER, E. J; CHEN, K. H; COKINS, G; LIN, T. W. Gestão estratégica de custos. 3. ed. São Paulo: McGrau-Hill, 2007.

COOPER, D. R; SCHINDLER, P. S. Métodos de Pesquisa em Administração. 7. ed. Porto Alegre: Bookman, 2003.

ELDENBURG, L. G; WOLCOTT, S. K. Gestão de custos: como medir, monitorar e motivar o desempenho. Rio de Janeiro: LTC, 2007.

FILIPPINI, F. Modelos de custos utilizados nas maiores indústrias de confecções da região oeste do Paraná. Dissertação (Mestrado). FURB - Universidade Regional de Blumenau. 2005. 
HORngren, C. T; DATAR, S . M; FOSTER, G. Contabilidade de custos. v. 1 e 2, 11.ed. São Paulo: Pearson Prentice Hall,v. 1 e 2, 2004.

HORnGRen, C. T;SUndEM, G. L; STRATTON, W. O. Contabilidade gerencial. 12. ed. São Paulo: Pearson Prentice hall, 2004.

KASPCZAK, M. C. M; SCANDELARI, L. Um estudo exploratório sobre a utilização das informações de custos em indústrias de confecções na cidade de Ponta Grossa. Journal of Technology Management \& Innovation. Vol 2, No 3 (2007), pp. 124-133

MARTINS, E. Contabilidade de custos. 9. ed. São Paulo: Atlas, 2008.

PONTE, V. M. R; RICCIO, E. L; LUSTOSA, P. R. B. Uma análise comparativa entre a "contabilidade de ganhos throughput accounting" e o "método do custeio variável". $<$ http://www.tecsi.fea.usp.br/riccio/artigos/pdf/analise_comparativa.pdf>. Acesso em: 05 jan 2009.

RICHARDSON, R. J. Pesquisa social: métodos e técnicas. 3. ed. São Paulo: Atlas: 2007

VANDERBECK, E. J; NAGY,C. F. Contabilidade de custos. 11.ed. São Paulo: Pioneira Thomson Learning, 2001.

\section{Dados dos autores:}

Nome completo: Laurindo Panucci Filho

Filiação institucional: UFPR - Universidade Federal do Paraná

Departamento: Ciências Sociais Aplicadas

Função ou cargo ocupado: Mestrando do Programa de Mestrado em Contabilidade

Endereço completo para correspondência (bairro, cidade, estado, país e CEP): Universidade Federal do Paraná, Departamento de Contabilidade; Av. Prefeito Lothario Meissner, 632; Jardim Botanico 80210-170 - Curitiba, PR - Brasil

Telefones para contato: (41) 9838-7449 / (44) 9917-6058

e-mail:laurindopanucci@hotmail.com

Nome completo: Simone Bernardes Voese

Filiação institucional: UFPR - Universidade Federal do Paraná

Departamento: Ciências Sociais Aplicadas

Função ou cargo ocupado: Docente no Programa de Mestrado em Contabilidade

Endereço completo para correspondência (bairro, cidade, estado, país e CEP): Universidade Federal do Paraná, Departamento de Contabilidade; Av. Prefeito Lothario Meissner, 632; Jardim Botanico 80210-170 - Curitiba, PR - Brasil

Telefones para contato: (41) 3360-4419

e-mail:sbs1611@hotmail.com

Recebido para publicação em: 10/10/2010

Aceito para publicação em: 26/11/2010 